This item was submitted to Loughborough's Research Repository by the author.

Items in Figshare are protected by copyright, with all rights reserved, unless otherwise indicated.

\title{
Chitosan and Poly (Vinyl Alcohol) microparticles produced by membrane emulsification for encapsulation and $\mathrm{pH}$ controlled release
}

\section{PLEASE CITE THE PUBLISHED VERSION}

http://dx.doi.org/10.1016/j.cej.2015.12.024

\section{PUBLISHER}

(C) Elsevier

VERSION

AM (Accepted Manuscript)

\section{PUBLISHER STATEMENT}

This work is made available according to the conditions of the Creative Commons Attribution-NonCommercialNoDerivatives 4.0 International (CC BY-NC-ND 4.0) licence. Full details of this licence are available at: https://creativecommons.org/licenses/by-nc-nd/4.0/

\section{LICENCE}

CC BY-NC-ND 4.0

\section{REPOSITORY RECORD}

Morelli, Serena, Richard Holdich, and Marijana Dragosavac. 2016. "Chitosan and Poly (vinyl Alcohol) Microparticles Produced by Membrane Emulsification for Encapsulation and Ph Controlled Release”. figshare. https://hdl.handle.net/2134/20490. 
Dear Author,

Please, note that changes made to the HTML content will be added to the article before publication, but are not reflected in this PDF.

Note also that this file should not be used for submitting corrections. 


\title{
Chitosan and Poly (Vinyl Alcohol) microparticles produced by membrane emulsification for encapsulation and $\mathrm{pH}$ controlled release
}

\author{
S. Morelli, R.G. Holdich, M.M. Dragosavac* \\ Department of Chemical Engineering, Loughborough University, Leicestershire LE11 3TU, UK
}

\section{H I G H L I G H T S}

- Membrane emulsification was used for the formulation of polymeric drops.

- Membrane with sharp pore openings produced smaller and more uniform drops.

- Glutaraldehyde was used for chemical crosslinking of the liquid droplets.

- Uniform and pH sensitive microparticles were produced using chitosan and PVA.

- Degree of crosslinking and chitosanPVA blends influenced the release.

\section{A R T I C L E I N F O}

\section{Article history:}

Received 17 September 2015

Received in revised form 22 November 2015 Accepted 10 December 2015

Available online $\mathrm{xxxx}$

\section{Keywords:}

Membrane emulsification

$\mathrm{W} / \mathrm{O}$ emulsions

Membrane pore geometry

pH sensitivity

Controlled release

\section{G R A P H I C A L A B S T R A C T}

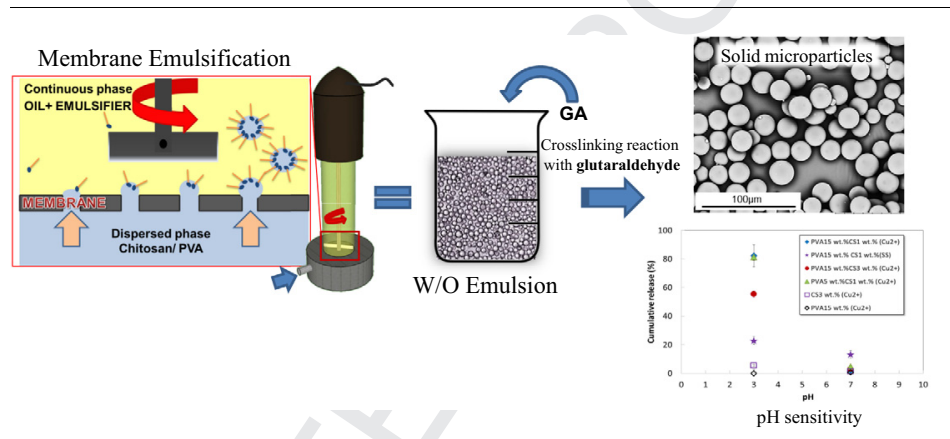

\begin{abstract}
A B S T R A C T
The Dispersion Cell membrane emulsification technique was used for the production of w/o emulsions with controlled droplet size and narrow size distribution. The influence of the operating parameters of the process was investigated. Varying the dispersed phase flux $\left(10-1250 \mathrm{~L} \mathrm{~h}^{-1} \mathrm{~m}^{-2)}\right.$ and the shear stress (2-59 Pa), droplets between 30 and $280 \mu \mathrm{m}$ were produced with $C V$ s as low as $18 \%$. Nickel and stainless steel membranes were used for the membrane emulsification. Pore geometry influenced the droplet size as well as uniformity and a normally hydrophilic stainless steel membrane with sharp pore openings produced more uniform and smaller drops compared to a PTFE coated hydrophobic nickel membrane with a conical pore surface. For the dispersed phase $15 \mathrm{wt} . \%$ PVA or 1-3\% wt.\% chitosan as well as their blends in water were used. Surfactants PGPR and ABIL EM90 were tested to determine their capability to form stable emulsions in Miglyol 840. PGPR could not be used to stabilize the emulsion with chitosan as the dispersed phase, probably due to the chemical interference between the carboxyl group present in the PGPR and chitosan. Solid microparticles were obtained by chemical crosslinking with glutaraldehyde (GA) at different concentrations (1-50 vol.\%). Particles crosslinked using less than 10 vol.\% GA were able to swell and release encapsulated compounds. Acid sensitive particles were produced by blending the PVA and chitosan. Up to $80 \%$ of $\mathrm{Cu}^{2+}$ and $20 \%$ of sodium salicylate was released from the particles under acidic conditions. No significant release was determined under neutral conditions.
\end{abstract}

(C) 2015 Published by Elsevier B.V.
Abbreviations: PVA, Poly (Vinyl Alcohol); PVAc, Poly Vinyl Acetate; CV, coefficient of variation; CS, chitosan; Miglyol 840, propyleneglycol dicaprylate/dicaprate; PGPR, polyglycerol polyricinoleate; ABIL EM 90, modified polyether-polysiloxane; GA, glutaraldehyde; AAS, Atomic Absorbance Spectrophotometer; SS, sodium salicylate.

* Corresponding author at: Chemical Engineering Department, Loughborough University, Loughborough LE113TU, UK. Tel.: +44 (0) 1509222501.

E-mail address: M.Dragosavac@lboro.ac.uk (M.M. Dragosavac).

\section{Introduction}

Formulation of polymeric particles for the purpose of drug release systems has received increased interest over recent years [1]. Conventional oral drug administration methods, such as solutions, suspensions, tablets, capsules [2], often do not provide protection from the acidic environment present in the stomach [2] 
and do not provide a constant therapeutic blood concentration of the drug over time $[3,4]$. A re-administration of the drug is required and the possibility of drug reaching the toxic levels. Encapsulating the drug into a polymeric matrix makes it possible to tailor the release, obtaining a site-specific release, prolonged action and/or sustained release $[5,6]$. The use of polymers enables the production of formulations able to respond to specific environmental stimuli such as $\mathrm{pH}$ [7], temperature [8] and magnetic fields [9]. The capability to release a drug depending on the $\mathrm{pH}$ can be exploited to tailor the release in a specific part of the gastro-intestinal tract, the $\mathrm{pH}$ in the stomach varies from 1.5 to 3.5 , while entering the intestine the $\mathrm{pH}$ varies from 5 to 7.5 [2]. $\mathrm{pH}$ dependent release can be very useful for the administration of medicines that have the stomach as the site of action and that can be potentially dangerous for the intestine [10]. Chitosan is a $\mathrm{pH}$ sensitive polysaccharide which has been extensively used for the tailoring of active compounds in the stomach [11], on its own or forming interpenetrating polymer network hydrogels [12] with other polymers [13-15]. Chitosan is the deacetylated form of chitin (poly- $\beta-(1 \rightarrow 4)-\mathrm{N}$-acetyl-D-glucosamine), the second most abundant polymer in nature [11,14]. The molecular weight and degree of acetylation determines the properties of chitosan [14]. Because of its biocompatibility, biodegradability, low cost and ability to open intercellular tight junctions, this polymer is a valuable excipient for oral drug delivery systems [16]. The presence of amino groups is the key factor that makes the polymer sensitive to $\mathrm{pH}$ variation: below their pKa (6.3) the amino groups of chitosan become positively charged, leading to swelling of the polymer in relation to two principal mechanisms: a mass transfer in the bulk of the polymer, and an electrostatic repulsion among the polymeric chains [15]. The process of swelling in acidic environment and the subsequent de-swelling in neutral-basic environment is called dynamic swelling [15]. These characteristics make chitosan an effective polymer for the production of $\mathrm{pH}$ sensitive formulations. Solid chitosan microparticles can be produced by crosslinking the polymer ionically or covalently [17]. Covalent crosslinking involves the formation of chemical bridges between polymeric chains; using bifunctional reagents such as glyoxal or glutaraldehyde. Berger et al. [17] reported a decrease in pH sensitivity of chitosan when covalently crosslinked due to most of the amino groups present in chitosan reacting with the crosslinker. The addition of another polymer able to react with the glutaraldehyde, can reduce the chitosan crosslinking density and increase the number of protonable amino groups available [17]. Poly (Vinyl Alcohol) is a water soluble, biocompatible and pharmaceutically approved [18] polymer that also reacts with glutaraldehyde producing a material with proven stability in both highly acidic and highly alkaline conditions [19]. Poly (Vinyl Alcohol) has a chemical structure with pendant hydroxyl groups originated from the hydrolysis of Poly Vinyl Acetate (PVAc) [20]. Crosslinked Poly (Vinyl Alcohol) on its own has the capability to sorb water and swell [20]; allowing drug dispersed within the polymeric matrix to diffuse out, but it does not show pH sensitivity [21,22]. Particles made of only Poly (Vinyl Alcohol) can be suitable for the release of active molecules with time [3] depending on the extent of the crosslinking reaction [20,22]. For the production of $\mathrm{pH}$ sensitive formulation, blends of chitosan and PVA can be produced, combining the Poly (Vinyl Alcohol) chemical, thermal and physical stability with the $\mathrm{pH}$ sensitivity of chitosan $[14,15,23]$. In the work presented here an alternative method for producing highly uniform particles with the desired dimensions was adopted: the particles were obtained by solidification of liquid polymeric droplets produced by membrane emulsification. Using this technique, emulsions are produced drop by drop injecting a dispersed phase through the pores of a membrane into the continuous phase using low shear. With this method it is possible to produce uniform sized droplets ( $C V$ of $10-20 \%$ ) [24]; by modifying some of the operating parameters of the process $[25,26]$. Furthermore, membrane emulsification overcomes some of the disadvantages typical of the classical methods of emulsion production such as: unreliable scale-up, insufficient droplet uniformity, mechanical stress due to high forces applied (high shear), and poor batch to batch reproducibility [27]. The possibility to use low shear stress for droplet production has great advantage in pharmaceutical and biological applications when delicate and/or shear sensitive materials as well as thermosensitive substances should be emulsified. Compared to other methods for drop by drop generation: microchannels and microfluidics; which can produce drops with CV below 5\% [24], membrane emulsification as a process has far greater productivity and can be scaled up [24,28].

Chitosan particles (but not blended with PVA) have been obtained by membrane emulsification [29] for the encapsulation of sensitive compounds such as insulin [30] or proteins [31]. For their production cross-flow membrane emulsification [32] in combination with tubular ceramic (SPG) membranes was used [32]. Cross-flow membrane emulsification, where the shear is induced by the recycled flow of the continuous phase, is not appropriate for the production of droplets larger than $20 \mu \mathrm{m}$, due to droplet break up in the pump. In addition, SPG membranes have highly tortuous pores [24] which can be fouled quite quickly and operate under very low transmembrane flux [24].

In the present work an alternative membrane emulsification system The Dispersion Cell $[33,34]$ has been used for production of $\mathrm{w} / \mathrm{o}$ emulsions in combination with microsieve membranes (metal foils with straight through pores) which are less prone to fouling compared to the SPG and ceramic membranes [24] and operate under higher transmembrane fluxes [24]. SPG and ceramic membranes are brittle and therefore their use is limited in food and pharmaceutical applications. In the literature the Dispersion Cell has been mainly reported for production of o/w emulsions [32,35-37]. Up to date only two papers deal with generation of w/o emulsions to produce silica [38], and alginate [8] particles therefore we investigate the most suitable microsieve membranes for production of w/o emulsions (hydrophobic nickel and stainless steel) in combination with formulation to obtain the most uniform polymeric droplets (chitosan (CS), Poly Vinyl Alcohol (PVA) or PVA-CS blends) in an oil continuous phase. A new strategy combining the crosslinking with emulsion generation has been developed the polymeric composition and the crosslinking.

\section{Materials and methods}

\subsection{Materials}

The oil phase in the w/o emulsion was produced by mixing Miglyol 840 (propyleneglycol dicaprylate/dicaprate SASOL, Germany) with oil soluble surfactants: 2 wt.\% PGPR, polyglycerol polyricinoleate, (ABITEC, USA) or 2 wt.\% ABIL EM 90, modified polyether-polysiloxane, (EVONIC industrials, Germany). The water phase in the w/o emulsions contained either pure Poly (Vinyl Alcohol) (PVA) (MW 13.000-23.000 g/mol, degree of hydrolysis $87-88 \%$ Sigma Aldrich, UK) or PVA and CS blends. PVA solution was prepared by dissolving predetermined amounts of PVA in warm water $\left(70-80^{\circ} \mathrm{C}\right) 0.1 \mathrm{M} \mathrm{HCl}$ (Fisher Scientific, UK). CS is soluble is slightly acidic solutions with a pH below 6 . The solubility of CS depends on the charge of the polymer: the acidic environment protonates the amino groups making the polymer water soluble, on the other hand, if the $\mathrm{pH}$ is increased the polymer loses the charge and becomes essentially hydrophobic [39]. CS was dissolved in warm $\left(50-60{ }^{\circ} \mathrm{C}\right) 6$ vol.\% acetic acid. After solubilization the polymeric to produce particles having different release profiles depending on Sigma Aldrich, UK), chitosan (CS) (MW 50.000-190.000 g/mol 
solutions were cooled to room temperature and blended to appropriate ratios. Final solutions were stirred constantly for at least $2 \mathrm{~h}$. Where appropriate, the inner water phase contained $5000 \mathrm{ppm}$ of $\mathrm{Cu}^{2+}$; with 20,000 $\mathrm{ppm}$ of $\mathrm{CuSO}_{4} \times 5 \mathrm{H}_{2} \mathrm{O}(\mathrm{MW}=249.685 \mathrm{~g} / \mathrm{mol})$ or $13,500 \mathrm{ppm} \mathrm{CuCl}_{2} \times 2 \mathrm{H}_{2} \mathrm{O}(\mathrm{MW}=170.48 \mathrm{~g} / \mathrm{mol}$ both supplied by Fisher Scientific, UK) as a $\mathrm{Cu}^{2+}$ source, or 3000 ppm of sodium salicylate (SS) (MW = $160.11 \mathrm{~g} / \mathrm{mol}$ Sigma Aldrich, UK) was encapsulated as a model drug, in separate samples. As a crosslinker 50 wt.\% glutaraldehyde (GA) was used (Sigma Aldrich, UK) diluted as appropriate. The densities of both dispersed and continuous phases were measured. The viscosity of both dispersed and continuous phases were measured using a Rheometer AR100-N (TA instrument, USA), at $20^{\circ} \mathrm{C}$, using a cone-plate configuration. The cone geometry was $4 \mathrm{~cm}$ in diameter, $1.59^{\circ}$, with a truncation of $56 \mu \mathrm{m}$. The equilibrium interfacial tensions at the water/oil interface were done by the Du Nouy ring method [40] using a White Electric Instrument tensiometer (model DB2KS). The physical properties of the surfactant solutions and the equilibrium interfacial tensions are listed in Table 1.

\subsection{Methods}

\subsubsection{Dispersion Cell and membranes}

The w/o emulsion was produced using the Dispersion Cell and flat disc metal membranes (Fig. 1(a)) supplied by Micropore Technologies Ltd. (Derby, UK). A two blade paddle stirrer (governed by DC power supply INSTEK, model: PR3060) placed above the membrane provided the rotation speed (300-2000 rpm) and subsequently the shear $(2-59 \mathrm{~Pa})$ needed for droplet detachment. Production of $\mathrm{w} / \mathrm{o}$ emulsions using membrane emulsification is challenging and membrane wetting should be avoided therefore PTFE coated hydrophobic nickel and stainless steel membranes (Micropore Technology Ltd., Derby, UK), both having different top surfaces, have been investigated. Membranes with $10 \mu \mathrm{m}$ pore diameter and $200 \mu \mathrm{m}$ pore spacing were mainly used, except where reported differently.

\subsubsection{Experimental procedure}

The w/o emulsion was prepared using a stationary disc membrane placed in the bottom of the Dispersion Cell (Fig. 1(a)). The polymeric water phase was injected through the membrane using the syringe pump (World Precision Instrument Inc., AL-1000, UK) using fluxes between 12 and $1250 \mathrm{~L} \mathrm{~h}^{-1} \mathrm{~m}^{-2}$. Previous work by Pan et al. 2012 [41] showed that the contact angle of the hydrophilic membrane can be changed so the membranes were pre-soaked in Miglyol (pure continuous phase) for at least $30 \mathrm{~min}$ to increase the hydrophobicity of the membrane surface. The initial volume of continuous oil phase in the cell was $100 \mathrm{~cm}^{3}$ and the experiments were run until the dispersed phase concentration reached 10 vol.\%. Once the desired amount of aqueous phase had passed through the membrane, both the pump and the agitator were switched off, the droplets were collected and analyzed. The membrane was cleaned initially $5 \mathrm{~min}$ in an ultrasonic bath using hot soapy water followed by 5 min washing in 2 wt.\% citric acid. The membrane was then rinsed with distilled water and dried using compressed air and left in continuous phase to promote the hydrophobicity of the surface. To produce solid microparticles the liquid droplets were solidified by chemical crosslinking using GA. A secondary emulsion (composed by a predetermined concentration of GA in water dispersed in the continuous phase) was prepared in a separate beaker using a homogenizer (IKA ${ }^{\circledR}$ T 10 ULTRATURRAX $^{\circledR}$, Germany) operating at 30,000 RPM for 3 min (giving droplets sized between 5 and $20 \mu \mathrm{m}$ ). The volume ratio of GA solution and continuous phase in the secondary emulsion was $1: 1$. The volume ratio GA: polymer was $1: 1$. Primary emulsion of polymeric droplets produced in the Dispersion Cell was then mixed with secondary emulsion of GA using magnetic stirring in a separate beaker for $90 \mathrm{~min}$ (Fig. 1(b)). In order to observe the internal structure particles were mounted in a resin and cut into slices using a Base Slege Microtome (Leitz, Weitezer, UK). Particle cross section was observed under an SEM and revealed solid and homogeneous internal structure. When PVA solution was used as the dispersed phase, the reaction occurred at room temperature, while for the blends of PVA and CS as well as pure CS solution the temperature needed to be elevated to $75^{\circ} \mathrm{C}$. By homogenizing the crosslinker with the continuous phase at very high shear it was possible to obtain very small droplets of GA. In this way the surface area of GA droplets was increased promoting the GA diffusion through the continuous phase consequently reacting with the aqueous polymeric droplets. The secondary GA emulsion was gently mixed with the primary polymer emulsion using a magnetic stirrer (Fig. 1 (b)). Using this method it was possible to avoid the "extraction step" reported by other authors $[42,43]$ which consists of the extraction of GA into organic solvents to make it miscible with the oil phase of the primary emulsion. After the solidification, the particles were washed with toluene or hexane, freeze dried and stored in air tight containers until further analysis. Due to the toxicity of GA it was important to determine that there is no residual GA left within the particles. To assay the presence of remaining GA, the polymeric particles were left in release medium $(\mathrm{pH}=3$ or

Table 1

Viscosities, densities and interfacial tensions measured for the different dispersed phase and continuous phase used for the production of the emulsions.

\begin{tabular}{|c|c|c|c|c|c|c|}
\hline \multirow[t]{2}{*}{ Continuous phase } & \multirow[b]{2}{*}{ Viscosity $\left(\mathrm{mPa} \mathrm{s}^{-1}\right)$} & \multirow[b]{2}{*}{ Density $\left(\mathrm{kg} \mathrm{m}^{-3}\right)$} & \multicolumn{2}{|l|}{ Dispersed phase } & \multirow[b]{2}{*}{ Density $\left(\mathrm{kg} \mathrm{m}^{-3}\right)$} & \multirow[b]{2}{*}{ Interfacial tension $\left(\mathrm{mN} \mathrm{m}^{-1}\right)$} \\
\hline & & & & Viscosity $\left(\mathrm{mPa} \mathrm{s}^{-1}\right)$ & & \\
\hline & & & PVA & & & \\
\hline Miglyol & 8.12 & 910 & 15 wt.\% & 99 & 1034 & 6.6 \\
\hline 2 wt.\% PGPR & 11.28 & & 15 wt.\% & 99 & 1034 & 2.2 \\
\hline \multirow{12}{*}{$\begin{array}{l}2 \text { wt.\% ABIL EM } 90 \\
\text { in Miglyol }\end{array}$} & & & 15 wt.\% PVA + 1 wt.\% CS & $\sim 500$ & 1045 & 3.1 \\
\hline & 8.38 & & $10 \mathrm{wt} . \%$ & 24 & 1022 & 1.6 \\
\hline & & & 15 wt.\% & 99 & 1034 & 2.1 \\
\hline & & & 20 wt.\% & 588 & 1045 & 2.7 \\
\hline & & & 25 wt.\% & 2550 & 1057 & 3.5 \\
\hline & & & Chitosan & & & \\
\hline & & & $1 \mathrm{wt} . \% \mathrm{CS}$ & 37 & 1008 & 1.7 \\
\hline & & & 2 wt.\% CS & 33 & 1014 & 2.2 \\
\hline & & & $3 \mathrm{wt} . \% \mathrm{CS}$ & $\sim 60$ & 1022 & 3.1 \\
\hline & & & 15 wt.\% PVA + 1 wt.\% CS & $\sim 500$ & 1045 & 2.6 \\
\hline & & & 5 wt.\% PVA + 1 wt.\% CS & 217 & 1015 & 2 \\
\hline & & & 15 wt. $\%$ PVA + 3 wt. $\%$ CS & $\sim 15,000$ & 1063 & $\mathrm{~N} / \mathrm{A}$ \\
\hline
\end{tabular}


(a)

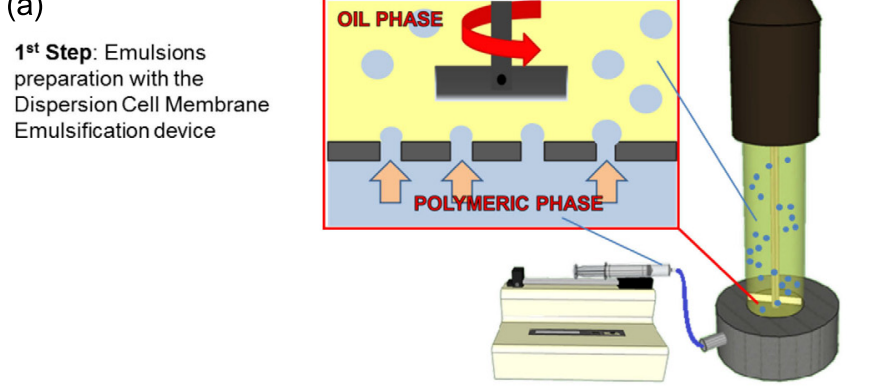

(b)

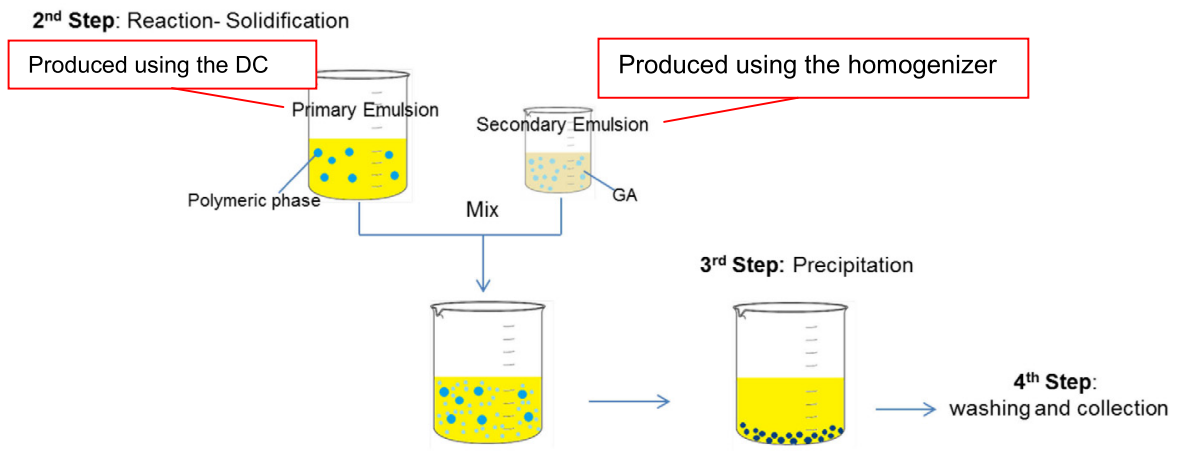

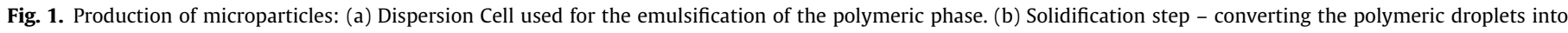
solid microparticles.

$\mathrm{pH}=7$ ) up to 5 days. The amount of GA present in the sample was analyzed with UV/VIS spectrophotometer operating at wavelength of $235 \mathrm{~nm}$ or $280 \mathrm{~nm}$ [44]. No signal corresponding to GA at those wavelengths was detected therefore it is believed that no unreacted GA was left in the particles. The sizes of freshly prepared droplets of dispersed phase in Miglyol, as well as solid particles were determined using a Leitz Ergolux optical microscope with an attached Pulnix TM-6CN monochrome camera. The droplets sometimes burst when placed on a microscopic slide due to surface tension effects, so photographs of the droplets had to be taken very quickly. For each experiment, numerous photos were taken and at least 300 droplets, or particles, were measured. As an indication of the droplet size distribution, the coefficient of variation (CV) was determined using the Java-based image processing package ImageJ. For each emulsion, three separate samples and measurements were produced and the mean average droplet size $D_{a v}$ is reported;

$D_{a v}=\sum_{i=1}^{n} \frac{d_{i}}{N}$

where $d_{i}$ is the $i$ th diameter of the droplet, and $N$ is the total number of the droplets counted. The coefficient of variation $(\mathrm{CV})$ was calculated accordingly to (2) for each emulsion produced; and reported to express the degree of uniformity.

$C V=\frac{\sum_{i=1}^{n}\left(d_{i}-D_{a v}\right) / N}{D_{a v}} \times 100(\%)$

\subsubsection{Swelling of the microparticles and in vitro release}

The swelling study was performed on the PVA particles crosslinked with different amounts of GA (1-50 vol.\%). $0.35 \mathrm{~g}$ of PVA particles were mixed with $20 \mathrm{ml}$ of swelling (release) media (phosphate buffer solution, $\mathrm{pH}=7.3$ ) and the samples were placed in a shaking water bath at $37^{\circ} \mathrm{C}$. After $24 \mathrm{~h}$ (no further change in particle size was observed) the excess of water was removed and the diameter of swollen particles was measured. For the in vitro release microspheres were produced using the polymeric solutions containing $\mathrm{Cu}^{2+}$ or SS. $0.35 \mathrm{~g}$ of now loaded microspheres (containing $350 \mathrm{mg}$ of $\mathrm{Cu}^{2+}$ or $1000 \mathrm{mg}$ of SS respectively) was placed in $20 \mathrm{ml}$ buffer solutions with pH values of 3 or 7 containing small amount of 2 wt.\% SDS (sodium dodecyl sulphate) added to the suspension to avoid particle agglomeration. At predetermined time intervals $5 \mathrm{ml}$ of the release media was removed and replaced with $5 \mathrm{ml}$ of fresh media to maintain the volume or the release media. The amount of $\mathrm{Cu}^{2+}$ released was assayed using an Atomic Absorbance Spectrophotometer (AAS) (Spectra AA-200 Varian, UK operating at wavelength of $244.2 \mathrm{~nm}$ ); while the SS concentration in the sample was measured using a UV-VIS spectrophotometer (Lambda 35 Perkin Elmer, UK operating at wavelength of $300 \mathrm{~nm}$ ). The amount of $\mathrm{Cu}^{2+}$ and SS was calculated from the corresponding calibration curves, made for each release media used. Samples in triplicate were averaged for each experiment. The cumulative release percentage was calculated as follows:

$C R=\frac{V_{t} \sum_{i=1}^{n-1} C_{i}+V_{o} C_{n}}{m} \times 100(\%)$

where $V_{o}$ is the volume of the release media $(=20 \mathrm{~mL}), C_{n}$ is the concentration of the compound determined at a specific time interval, $V_{t}$ is the volume of the replaced media $(=5 \mathrm{~mL})$, and $C_{i}$ represents the concentration of the encapsulated compound in the previous sample. $m$ is the mass of the encapsulated compound in the sample.

\section{Results and discussion}

3.1. Effect of pore geometry and operating parameters on droplet size and uniformity

The effect of the dispersed phase flux as well as the shear stress using two metallic disk membranes: stainless steel and hydrophobic nickel. 15 wt.\% PVA in water was used as dispersed phase and on the formed droplets, their size and uniformity, was investigated 
the continuous phase was 2 wt.\% PGPR in Miglyol. CV and average droplet diameter are respectively shown in figures Fig. 2(a) and (b) as a function of the dispersed phase flux $\left(12-1250 \mathrm{~L} \mathrm{~h}^{-1} \mathrm{~m}^{-2}\right)$ and the shear stress applied on the membrane surface (22-59 Pa). Increase of the shear stress over the membrane surface resulted in decrease of the average droplet diameter $\left(D_{a v}\right)$, while an increase of the $D_{a v}$ was observed with the flux increase as previously seen by other authors $[34,36,45]$. For the nickel membrane the biggest droplets $(64 \mu \mathrm{m})$ were produced using the combination of the lowest shear (22 Pa) and $270 \mathrm{~L} \mathrm{~h}^{-1} \mathrm{~m}^{-2}$ as dispersed phase flux. Gradually the droplet size decreased down to $36 \mu \mathrm{m}$ when the shear was $59 \mathrm{~Pa}$, at the lowest flux applied $\left(10 \mathrm{~L} \mathrm{~h}^{-1} \mathrm{~m}^{-2}\right)$. When the lower flux was used the emulsions had a $C V$ below $40 \%$. Gradually increasing the flux gave an improvement in the uniformity with the $C V$ going down to $20 \%$. It is possible that due to the low flux not all pores of the membrane were active [32,35].

The uniformity of the droplets improved using the steel membrane, at comparable shear and flux conditions. In addition the droplets produced using the stainless steel membrane were overall smaller and more uniform (lower CV) at the same shear conditions compared to those produced using the nickel membrane. The $C V$ s of the emulsions produces with the stainless steel were all below $25 \%$. The lowest value of $C V$ obtained was $18 \%$ applying an intermediate shear ( $35 \mathrm{~Pa}$ ) and $270-430 \mathrm{~L} \mathrm{~h}^{-1} \mathrm{~m}^{-2}$ as dispersed phase flux. A $C V \sim 35 \%$ is only observed for the emulsion produced under very high shear (59 Pa) and flux $\left(430 \mathrm{~L} \mathrm{~h}^{-1} \mathrm{~m}^{-2}\right)$ but too large droplets can be broken under the high shear. It is also possible that due to the high flux the droplets grow too fast and the surfactant does not have enough time to reach the interface before droplet detachment [32].

In order to predict the droplet diameter for a different values of shear stress, a mathematical model (Eq. (4)) introduced by Kosvintsev [30] was used. This model takes into account the presence of two forces acting on a growing droplet at the membrane surface. These forces are: the capillary force (which is proportional to the
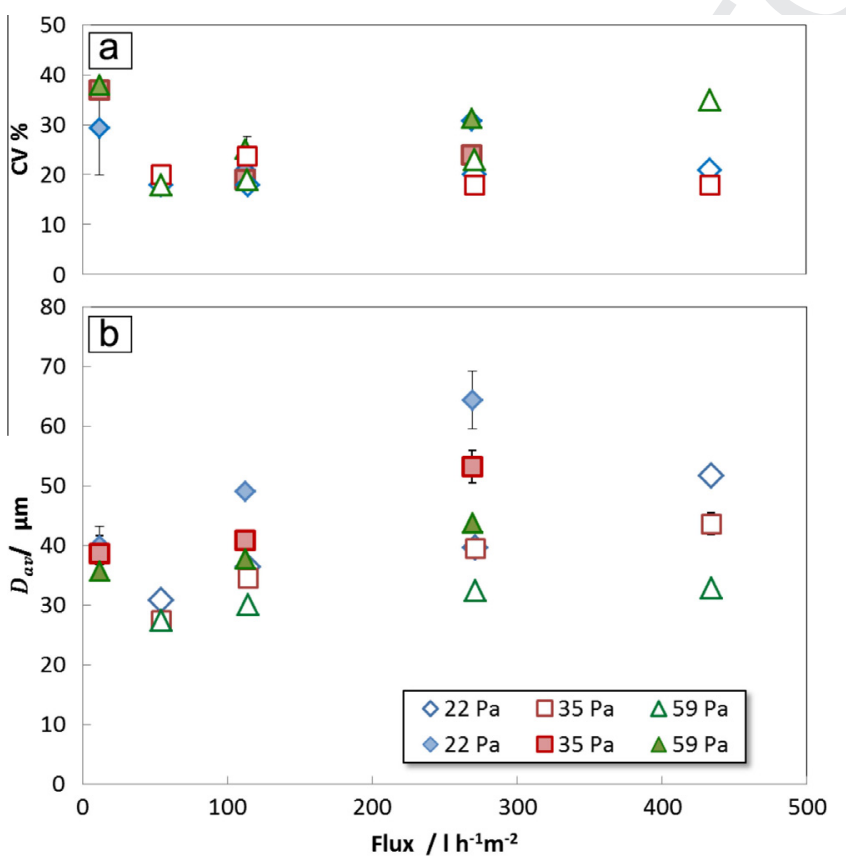

Fig. 2. Influence of the transmembrane flux and the shear stress: (a) coefficient of variation on the mean droplets diameter, (b) average droplet diameter $\left(D_{a v}\right)$; the hollow signs represent experiments performed using the $10 \mu \mathrm{m}$ stainless steel membrane; the full signs represent experiments performed using the $10 \mu \mathrm{m}$ nickel membrane. Dispersed phase 15 wt.\% PVA; continuous phase 2 wt.\% PGPR. value of interfacial tension between the two immiscible liquids) and the drag force: a function of the shear stress applied. Balancing these two forces it is possible to obtain the droplet size:

$D=\frac{\sqrt{18 \tau_{\max }^{2} r_{p}^{2}+2 \sqrt{81 \tau_{\max }^{4} r_{p}^{4}+4 r_{p}^{2} \tau_{\max }^{2} \gamma^{2}}}}{3 \tau_{\max }}$

where $D$ is the theoretical droplet diameter, $\tau_{\max }$ is the value of shear stress, $r_{p}$ is the pore radius and $\gamma$ represents the interfacial tension. $\tau_{\max }=0.825 \mu_{c} \omega r_{\text {trans }} / \delta$ where $\mu_{c}$ [Pa s] is the continuous phase viscosity, $r_{\text {trans }}$ is the transitional radius and $\delta$ is the boundary layer thickness $\delta=\sqrt{\mu_{c} / \omega \rho_{c}}$. The experimental values of droplet diameter were compared to the theoretical ones determined using the Eq. (4). In Fig. 3 the dotted curve shows the theoretical values of the $D_{a v}$ calculated using Eq. (4) at different shear stress. In the graph are reported the $D_{a v}$ obtained using the two membrane types and at different dispersed phase fluxes. It is noticeable that at very low values of flux the experimental values are closer to the theoretical ones. The shear - capillary model does not consider the dispersed phase flux as having an influence on the final droplet size. However, an increase of the flux produces a gradually higher divergence between the experimental droplet size and the model predicted ones. The influence of the dispersed phase flux on the drop formation and detachment has been previously investigated by Schröder and Schubert (1999) [46]. According to Schröder and Schubert (1999) the droplets formed on the membrane surface are influenced by the number of the active pores on the membrane surface. The number of active pores within the model has to be estimated which is an additional fitting parameter which needs to be taken into consideration [45] and therefore correlating size with flux has been avoided in this work.

Contact angles were measured for water and $15 \mathrm{wt} . \%$ PVA on hydrophobic nickel and stainless steel membranes and the results are reported in Table 2 . In addition the photographs of the droplets sitting on different membrane surfaces are reported within Fig. 3. According to the contact angle measurements the PVA droplet wets the stainless membrane far more than the nickel membrane (Fig. 3(a) and (b)). The stainless is more hydrophilic than the nickel and, therefore, one would assume that it is more likely to wet than the nickel with the dispersed phase. Hence, the smaller drops, and better size distribution, coming from the stainless membrane, cannot be attributed to the membrane surface wetting properties: the results are the wrong way round - nickel is more hydrophobic and

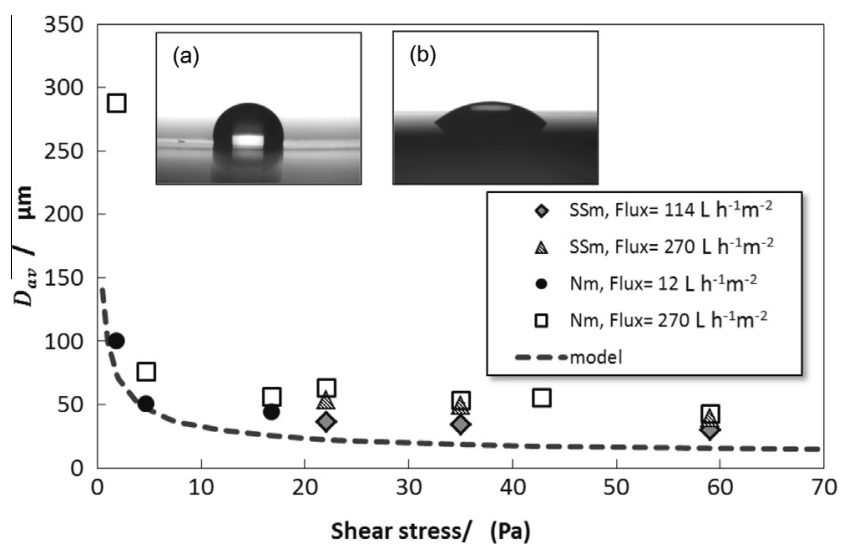

Fig. 3. Comparison between the theoretical droplet size calculated using the model (Eq. (4)) (dashed line) and the average droplet diameter obtained under different conditions of shear and transmembrane flux. Nm - nickel membrane, SS - stainless steel membrane dispersed phase (DP) 15 wt.\% PVA; continuous phase (CP) 2 wt.\% PGPR. (a) 15 wt.\% PVA droplet on the hydrophobic nickel membrane. (b) 15 wt.\% PVA on the stainless steel membrane. 
Table 2

Contact angle measurements (dispersed phase on the membrane surface).

\begin{tabular}{llc}
\hline Membrane & Dispersed phase & Theta(average)(deg) \\
\hline Hydrophobic nickel & Pure water & $122.2 \pm 0.09$ \\
Hydrophobic nickel & 15 wt.\% PVA & $102.7 \pm 0.10$ \\
Stainless steel & Pure water & $60.1 \pm 0.72$ \\
Stainless steel & 15 wt.\% PVA & $40.8 \pm 0.39$ \\
\hline
\end{tabular}

should wet better with the oil phase. Fig. 4 shows both membranes with the nickel membrane showing a conical surface above the pores (lines within SEM image, Fig. 4(a-c)). This contrasts with the pores of the stainless membrane which have sharp openings without conical configuration (Fig. 4(d-f)). Thus the smaller and more uniform drops are more likely to be a consequence of the sharp pore opening; i.e. flat membrane surface. In addition all these polymeric phases are highly acidic therefore the use of the stainless steel as membrane material is advantageous as it is more resistant to acidic $\mathrm{pH}$ than nickel.

\subsection{Effect of surfactant present in the continuous phase}

Droplets stability is not greatly affected by the membrane type, but it is by the emulsifier used. PGPR and alternatively ABIL EM 90 were used to stabilize the aqueous phase in Miglyol. When pure PVA (15 wt.\%) was used as a dispersed phase, 2 vol.\% PGPR produced uniform emulsions with high uniformity (Fig. 5(a)); slightly less uniform, but stable emulsions were obtained using 2 vol.\% ABIL EM 90 as stabilizer (Fig. 5(b)) and PVA (15 wt.\%). Using the same composition of the continuous phase, PVA and CS in water (ratio 15:1) were used as dispersed phase and the resulting emulsion is shown in Fig. 5(c), it was unstable and the presence of very big droplets was observed. It is hypothesized that after the emulsification process the droplets start to coalesce due to interaction of CS with the stabilizer. The hydrophilic part of PGPR contains polyricinoleic acid, characterized by the presence of groups - $\mathrm{COOH}$. An interaction between carboxylic group and the CS amino group in an acidic environment can occur, destabilizing the emulsifier and interfering with its action. Thus, a slight increase of the interfacial tension was measured for the system when PGPR was used as emulsifier (Table 1). The blend of PVA and CS (15:1) was emulsified with continuous phase composed by 2 vol.\% ABIL EM 90 in Miglyol (Fig. 5(d)). In this case the resulting emulsion was more stable. The uniformity was not as good as in Fig. 5(a) and (b), but the stability was improved (no obvious coalescence found). It was not possible to use the $10 \mu \mathrm{m}$ pore size stainless steel membrane for the emulsification of the polymeric phase composed by the two polymer blends (15:1) due to the high viscosity of this phase. This limited the work with the polymer blends to the nickel membranes with larger pore size $(20 \mu \mathrm{m})$ (Fig. 5(b) and (d)).

\subsection{Effect of crosslinker on final solid particles}

The crosslinking reaction with GA is a condensation polymerization that links the polymeric chains. For higher degree of crosslinking the polymeric segments are more interconnected reducing the capability of the network to swell. The degree of crosslinking can be used to tailor the degree of swelling; the lower the degree of crosslinking the greater the degree of swelling [3]. Moreover, the amount of crosslinking has an influence on the release profile of a compound from the particles: the water is absorbed by the particles and due to the diffusion the encapsulated compound within the polymeric matrix is released. To study the influence of the crosslinker concentration on the swelling, microparticles with different degree of crosslinking were allowed to swell completely in water for $24 \mathrm{~h}$ in an oscillating bath at $37^{\circ} \mathrm{C}$. To produce the solid particles droplets were crosslinked using different amounts of GA (1-50 vol.\%) to determine the lowest concentration required to obtain solid microparticles. To ensure that the solid particles are formed, after a maximum 90 min of reaction, a sample of particles still in the oil phase of the emulsion was taken. The sample was washed with acetone and left at room temperature for few seconds to dry. Acetone dissolves the oil and removes the excess water, thus establishing if the dispersion was of droplets, or solidified particles which do not dissolve. The sample of particles was than observed with the microscope. The lowest GA concentration needed for solidification of the particles was 1 vol.\% of GA. The size of the dried particles crosslinked using different GA concentrations was measured and it was seen that the diameter was not affected by the amount of crosslinker used; the samples prepared with different GA concentrations had $D_{a v}=32 \pm 2 \mu \mathrm{m}, C V=20 \pm 2 \%$. Particles were prepared from emulsion with $D_{a v}=53 \pm 2 \mu \mathrm{m}, C V=20 \pm 2 \%$. According to Rathnbone et al. (2002) the average particle size of the microparticles used for oral drug delivery is between 20 and $120 \mu \mathrm{m}$ and particles used are within the range of particles size commonly used for oral drug delivery [47]. The SEM analysis of dried particles showed the corrugated surface, more evident for less crosslinked particles (Fig. 6). No swelling was observed for PVA particles crosslinked with 10 vol.\% GA or above. A cross section of the sliced particles observed on an SEM was solid and homogeneous therefore, it is believed that the GA can easily diffuse from the droplets of the secondary emulsion into the polymeric droplets of the primary emulsion. Having in mind that the droplets size is quite small GA molecules have quite short pathway for diffusion. Fig. 6 also presents the degree of swelling as a function of the amount of crosslinker used. Particle diameter was not influenced when the concentration of GA was between 10 and 50 vol.\%. Reducing the GA concentration for crosslinking of the particles below 5 vol.\% it was possible to produce particles which readily swell and able to incorporate water. At higher GA concentration the number of linkages between the polymeric chains is higher, reducing the ability of the polymeric network to absorb water.

\subsection{Effect of polymers on $\mathrm{Cu}^{2+}$ release}

To determine the release profile of a sample compound from the produced particles, $\mathrm{Cu}^{2+}$ was used. $\mathrm{Cu}^{2+}$ was chosen since it is a small ion that is easy to detect by AAS and previous papers have used it as a drug analogue molecule [48]. The use of AAS to determine the concentration of $\mathrm{Cu}^{2+}$ enables even small changes of $\mathrm{Cu}^{2+}$ concentration with time to be monitored. The behaviour of the particles was studied in acidic conditions $(\mathrm{pH}=3)$ to mimic the gastric fluid, and neutral conditions ( $\mathrm{pH}=7$ ) to mimic the intestinal tract. Normally, the gastric emptying time is about 3-4 h [49], after a normal meal. Thus, the release was assayed up to $3 \mathrm{~h}$, required for possible drug absorption at stomach level. Fig. 7(a) shows the release of $\mathrm{Cu}^{2+}$ from 15 vol.\% PVA particles as a function of the time depending on the amount of GA used. The release of $\mathrm{Cu}^{2+}$ decreases with the increase of the crosslinker concentration; for example the particles prepared with 25 vol.\% of GA released less than $1 \%$ of $\mathrm{Cu}^{2+}$ after $3 \mathrm{~h}$, while the particles prepared with the 1 vol.\% of GA released up to $70 \%$ of $\mathrm{Cu}^{2+}$ in $3 \mathrm{~h}$. High initial release of $\mathrm{Cu}^{2+}$ was observed from the PVA particles, giving the so called "burst release" [50]. "Burst release" of $\mathrm{Cu}^{2+}$ in the early minutes, could be attributed to a diffusion of $\mathrm{Cu}^{2+}$ from the particles surface. It is interesting to notice that no release from PVA particles was observed if GA concentration for crosslinking was 10 vol.\% or above. But if the PVA was blended with CS even if the particles were crosslinked with 10 vol.\% GA it was possible to tailor the release as can be seen from the Fig. 7(b). Fig. 7(b) shows the release 


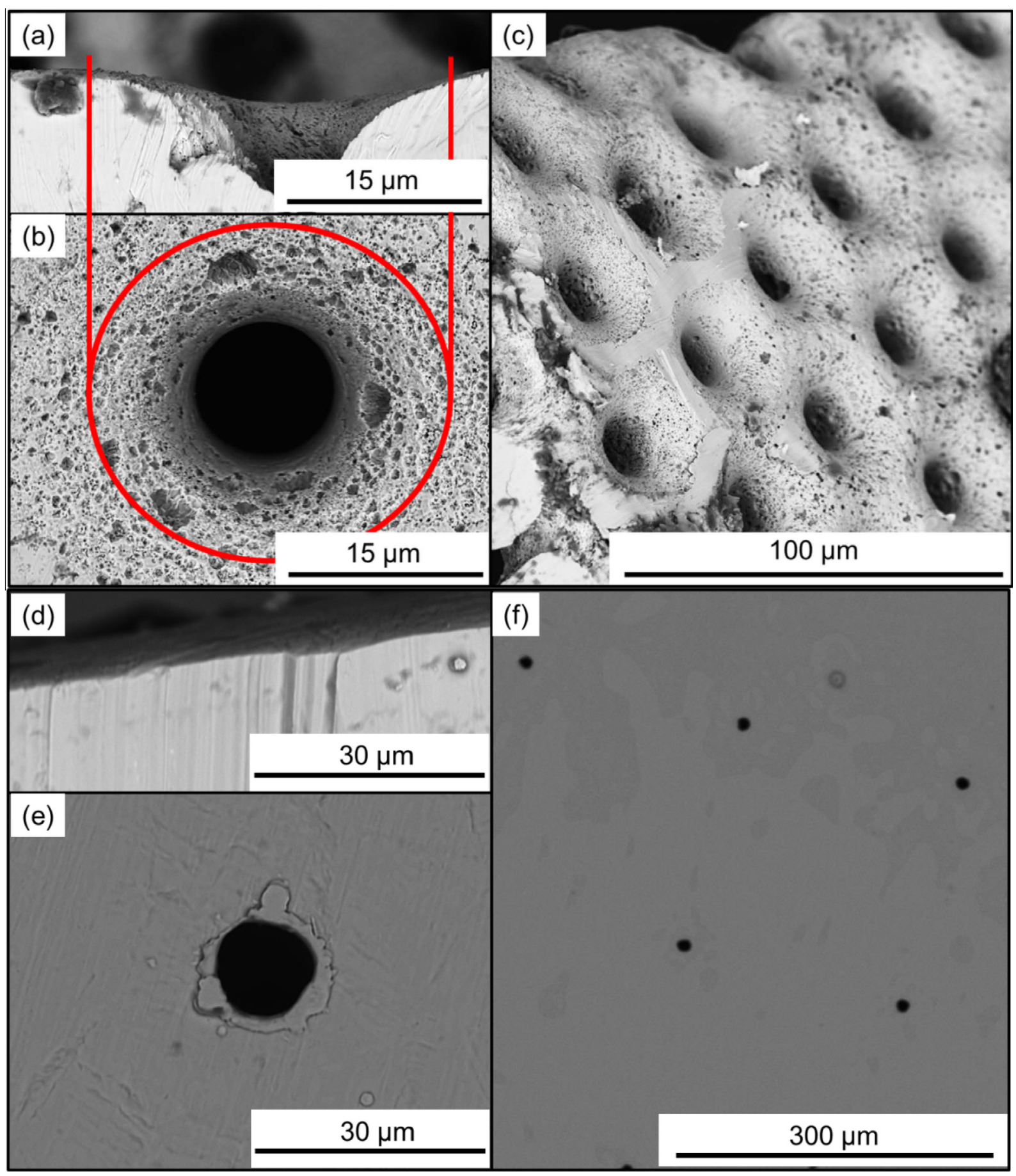

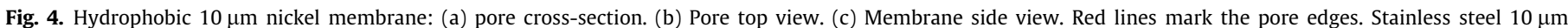

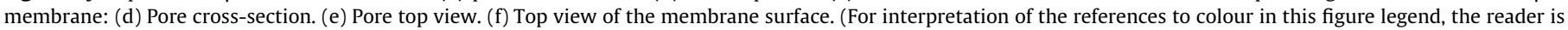
referred to the web version of this article.)

from particles made by either pure 15 vol.\% PVA, pure 3 vol.\% CS or PVA and CS blends. 10 vol.\% of GA was used for crosslinking of all particles within Fig. 7(b) and it was the lowest required concentration of crosslinker which allowed production of particles which kept their shape after solidification and drying. $\mathrm{Cu}^{2+}$ was released over time reaching up to $80 \%$ after $3 \mathrm{~h}$ depending on the polymeric blend, $10 \%$ more than when 15 vol.\% PVA was crosslinked with $1 \%$ GA (Fig 7(a)). When pure polymers were used almost no $\mathrm{Cu}^{2+}$ was released probably due to high crosslinking density. The sample made by the combination of 15 wt.\% PVA and 3 wt.\% of CS, gave intermediate release. Such behaviour could be attributed to the high viscosity of this polymeric phase (Table 1 ), which as a result produces more dense particles, less able to swell and release $\mathrm{Cu}^{2+}$. Highest release up to $80 \%$ was achieved when PVA was blended with $1 \% \mathrm{CS}$. To investigate the $\mathrm{pH}$ sensitive release, the particles were tested at $\mathrm{pH}=3$ and $\mathrm{pH}=7$, and the results are shown in Fig. 8. Particles made with pure PVA or pure CS (crosslinked with 10 vol.\% of GA) did not show any significant $\mathrm{Cu}^{2+}$ release no matter the $\mathrm{pH}$. When PVA was blended with CS higher release of $\mathrm{Cu}^{2+}$ was obtained at $\mathrm{pH}=3$. Particles produced blending PVA with $1 \%$ CS demonstrated the highest release at acidic conditions. Such $\mathrm{pH}$ dependent release can be attributed to protonation

Please cite this article in press as: S. Morelli et al., Chitosan and Poly (Vinyl Alcohol) microparticles produced by membrane emulsification for encapsulation and pH controlled release, Chem. Eng. J. (2015), http://dx.doi.org/10.1016/j.cej.2015.12.024 


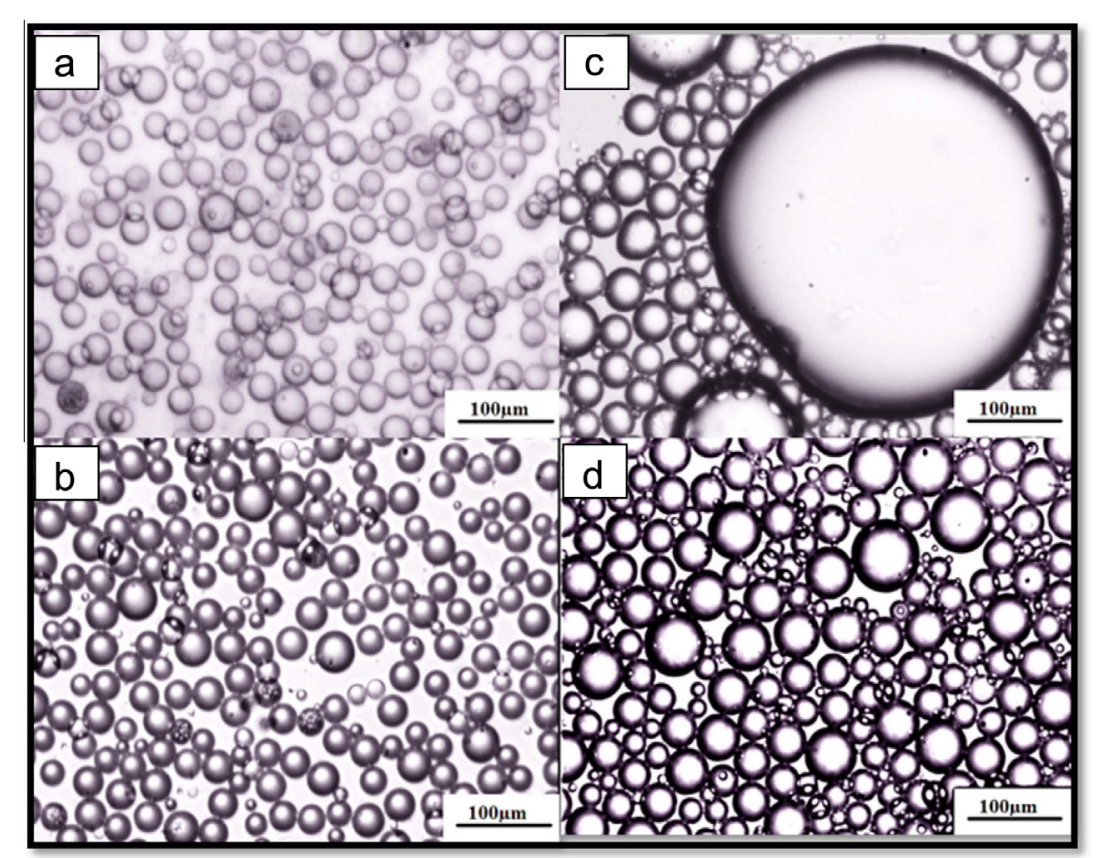

Fig. 5. Emulsions: (a) 2 wt.\% PGPR in Miglyol as continuous phase (CP) and 15 wt.\% PVA as dispersed phase (DP). (b) 2 wt.\% ABIL EM 90 in Miglyol as CP and 15 wt.\% PVA as DP. (c) 2 wt.\% PGPR in Miglyol as CP and PVA:CS 15:1 as DP. (d) 2 wt.\% ABIL EM 90 in Miglyol as CP and PVA:CS 15:1 as DP.

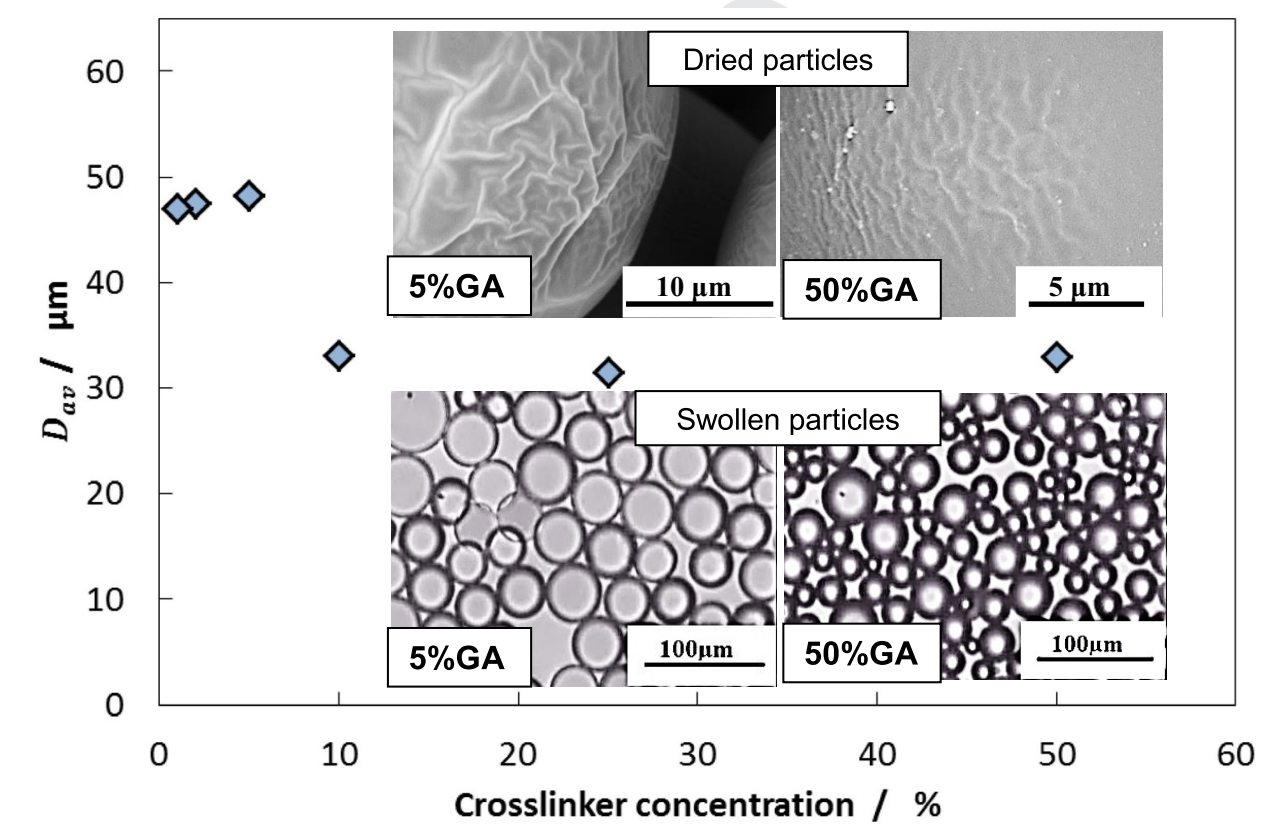

Fig. 6. Swelling proprieties of PVA particles crosslinked using GA solutions (1-50\%), expressed as value of $D_{a v}$ of the swollen particles in water. Top images - SEM's of dry crosslinked particles. Bottom images - optical microphotographs of swollen crosslinked particles. 5 vol.\% and 50 vol.\% GA solutions used respectively.

of amino groups of chitosan with the decrease of $\mathrm{pH}$ [17]. This protonation leads to chain repulsion, diffusion of proton and counter ions together with water inside the gel and dissociation of secondary reactions allowing swelling [17]. None of the samples swelled significantly at neutral conditions.

\subsection{Effect of the polymers on sodium salicylate release}

To study the behaviour of a real drug molecule, sodium salicylate (SS) was encapsulated within the PVA-CS particles crosslinked with 10 vol.\% of GA. The sample that gave the highest release of
$\mathrm{Cu}^{2+}$ was chosen (15 wt.\%PVA-1 wt.\%CS). The release was tested at $\mathrm{pH}=3$ and 7. As shown in Fig. 7(b), the release of SS is very slow reaching only $23 \%$ after three hours. SS is an anionic drug [51] $\left(\mathrm{MW}=160.11 \mathrm{~g} \mathrm{~mol}^{-1}\right.$ ) and it is hypothesized that in an acidic environment the ionic amino groups of CS can delay the release of SS, that can interact ionically with the charged group of CS. Comparing the release of $\mathrm{Cu}^{2+}$ with the SS, the delay of the SS release can be explained considering the drug-polymer ionic interaction [52] and the higher MW of SS. On the other hand, $\mathrm{Cu}^{2+}$ is a positively charged ion, which can be repelled from the CS polymeric matrix, facilitating release. In Fig. 8 the release of SS in acidic and

Please cite this article in press as: S. Morelli et al., Chitosan and Poly (Vinyl Alcohol) microparticles produced by membrane emulsification for encapsulation and pH controlled release, Chem. Eng. J. (2015), http://dx.doi.org/10.1016/j.cej.2015.12.024 


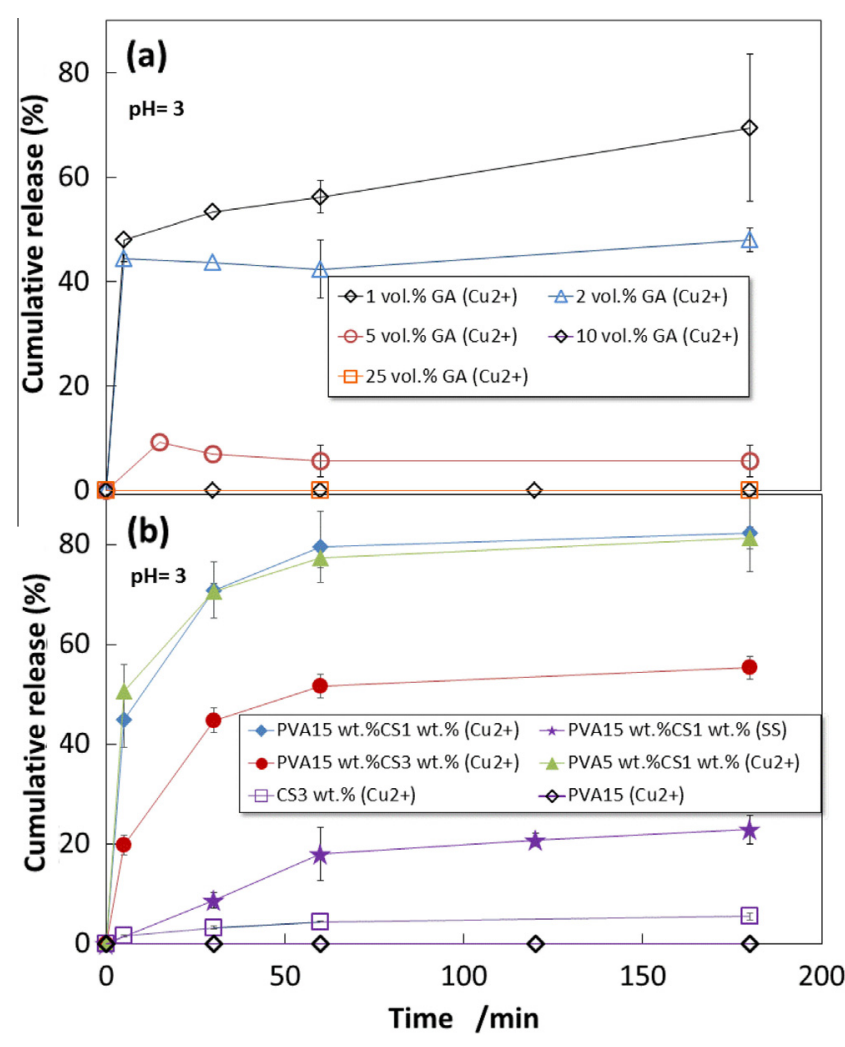

Fig. 7. Release study. (a) Influence of GA concentration on $\mathrm{Cu}^{2+}$ release from $15 \mathrm{vol}$. \% PVA particles. (b) Influence of the polymeric blends (PVA nad Chitosan) on $\mathrm{Cu}^{2+}$ and SS (sodium salicylate) release (10 vol.\% GA as crosslinker). In all experiments final particle size tested for all formulation was $30 \mu \mathrm{m} C V=20 \pm 2 \%$. All particles contained $5000 \mathrm{ppm}$ of $\mathrm{Cu}^{2+}$ or $3000 \mathrm{ppm}$ sodium salicylate where appropriate.

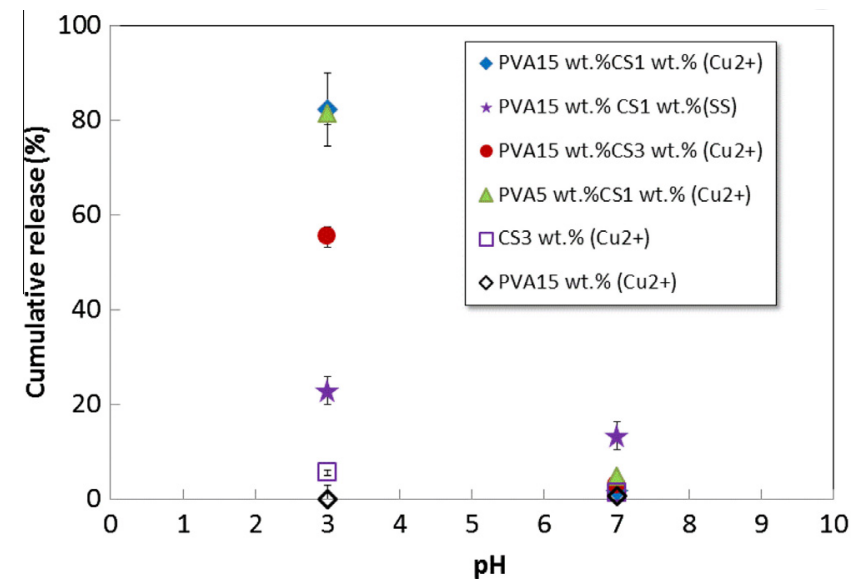

Fig. 8. $\mathrm{Cu}^{2+}$ or SS release in different $\mathrm{pH}$ conditions (10 vol.\% GA as crosslinker is used for all the samples). In all experiments final particle size tested for all formulation was $30 \mu \mathrm{m} \mathrm{CV}=20 \pm 2 \%$. All particles contained $5000 \mathrm{ppm}$ of $\mathrm{Cu}^{2+}$ or 3000 ppm sodium salicylate where appropriate.

neutral environment is reported, and little difference exists between the two release media. A small amount of SS was released at $\mathrm{pH}=7$ from the PVA-CS particles after $3 \mathrm{~h}$. However, this behaviour was expected since $\mathrm{CS}$ is not ionized at $\mathrm{pH}=7$ and the ionic interaction between the polymer and the SS do not occur. SS is released in a small quantity at $\mathrm{pH} 7$ probably from the surface of the particles. It must be considered that for CS based particles the type of drug encapsulated plays an important role as well as the crosslinker amount and the $\mathrm{pH}$ of the release medium.

\section{Conclusions}

Uniform emulsions were produced with the Dispersion Cell membrane emulsification technique, with a $C V$ of $18 \%$ under the best operating conditions (shear of $35 \mathrm{~Pa}$ and $270-430 \mathrm{~L} \mathrm{~h}^{-1} \mathrm{~m}^{-2}$ as dispersed phase flux). Modifying the operating parameters, it was possible to produce emulsions with droplets between 30 and $280 \mu \mathrm{m}$. Hydrophilic stainless steel membrane (pre-soaked in the oil continuous phase) produced smaller and more uniform droplets compared to a PTFE coated hydrophobic nickel membrane. Contact angle measurements confirmed the hydrophobicity of the nickel membrane therefore the pore surface (conical for the nickel and flat for the stainless steel membrane) had a greater influence on the size and uniformity - possibly with the drop forming on an area greater than the pore itself for drops produced using the nickel membrane. The minimum concentration of crosslinker needed for solidification was 1 vol.\% GA. The amount of GA affected the capability of the particles to sorb water and swell. This behaviour to swell is directly correlated to with the ability of the particles to release the encapsulated compound. PVA particles prepared with 1 vol.\% of GA released $70 \%$ of the encapsulated compound $\left(\mathrm{Cu}^{2+}\right)$ within $3 \mathrm{~h}$. The release profile of $\mathrm{Cu}^{2+}$ from the PVA particles was characterized by an initial "burst release", due to the release of $\mathrm{Cu}^{2+}$ from the surface of the particles. Blending chitosan and PVA it was possible to increase the release of $\mathrm{Cu}^{2+}$ up to $80 \%$ in $3 \mathrm{~h}$ under acidic conditions. No significant release (less than $3 \%$ ) was observed at neutral conditions. Due to the higher MW and the ionic interaction with the polymeric matrix the release of sodium salicylate was almost 4 times lower compared to $\mathrm{Cu}^{2+}$ after $3 \mathrm{~h}$ in acidic environment and around $10 \%$ in neutral environment. Thus, the encapsulation of negatively charged drugs (such as sodium salicylate) delays the release and affects the selective release in acidic $\mathrm{pH}$.

Our future work will focus on drug and cell encapsulation and we will consider the possibility to blend chitosan with other polymers such us alginate and gelatin in the formation of biocompatible and permeable hydrogels to promote drug release in the intestine. Different polymer coatings (e.g. EUDRAGIT ${ }^{\circledast}$ ) might be tested to provide stability in acidic environment followed by the release in intestine. Furthermore the emulsion production system will be scaled up in order to evaluate an increase in the productivity, and if the resulting particles are consistent with what is expected from the information obtained with the laboratory Dispersion Cell.

\section{Acknowledgments}

The authors want to acknowledge the support and help as well and fruitful discussions received from Dr Anna Trybala regarding the contact angle measurements performed on a DSA10, Kruss, Germany.

\section{References}

[1] S. Freiberg, X.X. Zhu, Polymer microspheres for controlled drug release, Int. J. Pharm. 282 (2004) 1-18.

[2] A.M. Hillery, A.W. Lloyd, J. Swarbrick, Drug Delivery and Targeting: For Pharmacists and Pharmaceutical Scientists, Taylor and CRC Press, 2002.

[3] D. Shah, Y. Shah, R. Pradhan, Development and evaluation of controlled-release diltiazem $\mathrm{HCl}$ microparticles using cross-linked poly (vinyl alcohol), Drug Dev. Ind. Pharm. 23 (1997) 567-574.

[4] A.S. Hoffman, The origins and evolution of "controlled" drug delivery systems, J. Control. Release 132 (2008) 153-163.

[5] W.M. Saltzman, Drug Delivery: Engineering Principles for Drug Therapy, Oxford University Press, 2001.

[6] S.S. Sagiri, V.K. Singh, I. Banerjee, K. Pramanik, P. Basak, K. Pal, Core-shell-type organogel-alginate hybrid microparticles: a controlled delivery vehicle, Chem. Eng. J. 264 (2015) 134-145.
600

601

602

603

604

605

606

607

608

609

610

611

612

613

614

615

616

617

618

619

620 
[7] S. Park, S. Hwang, J. Lee, pH-responsive hydrogels from moldable composite microparticles prepared by coaxial electro-spray drying, Chem. Eng. J. 169 (2011) 348-357.

[8] M.P. Hanga, R.G. Holdich, Membrane emulsification for the production of uniform poly-N-isopropylacrylamide-coated alginate particles using internal gelation, Chem. Eng. Res. Des. 92 (2014) 1664-1673.

[9] J. Dobson, Magnetic nanoparticles for drug delivery, Drug Dev. Res. 67 (2006) $55-60$.

[10] E.C. Nista, M. Candelli, F. Cremonini, I.A. Cazzato, M.A. Zocco, F. Franceschi, et al., Bacillus clausii therapy to reduce side-effects of anti-Helicobacter pylori treatment: randomized, double-blind, placebo controlled trial, Aliment. Pharmacol. Ther. 20 (2004) 1181-1188.

[11] R. Hejazi, M. Amiji, Chitosan-based gastrointestinal delivery systems, J. Control. Release 89 (2003) 151-165.

[12] E.S. Dragan, Design and applications of interpenetrating polymer network hydrogels. A review, Chem. Eng. J. 243 (2014) 572-590.

[13] M.V. Risbud, A.A. Hardikar, S.V. Bhat, R.R. Bhonde, pH-sensitive freeze-dried chitosan-polyvinyl pyrrolidone hydrogels as controlled release system for antibiotic delivery, J. Control. Release 68 (2000) 23-30.

[14] T. Wang, M. Turhan, S. Gunasekaran, Selected properties of pH-sensitive, biodegradable chitosan-poly(vinyl alcohol) hydrogel, Polym. Int. 53 (2004) 911-918.

[15] S. Gunasekaran, T. Wang, C. Chai, Swelling of pH-sensitive chitosan-poly(vinyl alcohol) hydrogels, J. Appl. Polym. Sci. 102 (2006) 4665-4671.

[16] L. Illum, Chitosan and its use as a pharmaceutical excipient, Pharm. Res. 15 (1998) 1326-1331.

[17] J. Berger, M. Reist, J.M. Mayer, O. Felt, N.a. Peppas, R. Gurny, Structure and interactions in covalently and ionically crosslinked chitosan hydrogels for biomedical applications, Eur. J. Pharm. Biopharm. 57 (2004) 19-34.

[18] C. DeMerlis, D. Schoneker, Review of the oral toxicity of polyvinyl alcohol (PVA), Food Chem. Toxicol. 41 (2003) 319-326.

[19] B. Bolto, T. Tran, M. Hoang, Z. Xie, Crosslinked poly(vinyl alcohol) membranes, Prog. Polym. Sci. 34 (2009) 969-981.

[20] C.M. Hassan, N.A. Peppas, Structure and applications of poly (vinyl alcohol) hydrogels produced by conventional crosslinking or by freezing/thawing methods, Biopolym. PVA Hydrogels, Anionic Polym. Nanocomposites (2000) 37-65.

[21] X. Yang, Q. Liu, X. Chen, F. Yu, Z. Zhu, Investigation of PVA/ws-chitosan hydrogels prepared by combined c-irradiation and freeze-thawing, Carbohydr. Polym. 73 (2008) 401-408.

[22] J. Varshosaz, N. Koopaie, Cross-linked poly (vinyl alcohol) hydrogel: study of swelling and drug release behaviour, Iran. Polym. J. 11 (2002) 123-131.

[23] K.S.V. Krishna Rao, B. Vijaya Kumar Naidu, M.C.S. Subha, M. Sairam, T.M. Aminabhavi, Novel chitosan-based $\mathrm{pH}$-sensitive interpenetrating network microgels for the controlled release of cefadroxil, Carbohydr. Polym. 66 (2006) 333-344.

[24] G.T. Vladisavljević, I. Kobayashi, M. Nakajima, Production of uniform droplets using membrane, microchannel and microfluidic emulsification devices, Microfluid. Nanofluid. 13 (2012) 151-178.

[25] G.T. Vladisavljević, R.A. Williams, Recent developments in manufacturing emulsions and particulate products using membranes, Adv. Colloid Interface Sci. 113 (2005) $1-20$

[26] E. Piacentini, E. Drioli, L. Giorno, Membrane emulsification technology: twenty-five years of inventions and research through patent survey, J. Membr. Sci. (2014).

[27] W. Liu, X. Yang, W.W. Ho, Preparation of uniform-sized multiple emulsions and micro/nano particulates for drug delivery by membrane emulsification, J. Pharm. Sci. 100 (2011) 75-93.

[28] M.A. Suárez, G. Gutiérrez, J. Coca, C. Pazos, Geometric parameters influencing production of $\mathrm{O} / \mathrm{W}$ emulsions using flat metallic membranes and scale-up, J. Membr. Sci. 430 (2013) 140-149.

[29] K. Akamatsu, D. Kaneko, T. Sugawara, R. Kikuchi, S.I. Nakao, Three preparation methods for monodispersed chitosan microspheres using the shirasu porous glass membrane emulsification technique and mechanisms of microsphere formation, Ind. Eng. Chem. Res. 49 (2010) 3236-3241.

[30] L.-Y. Wang, Y.-H. Gu, Q.-Z. Zhou, G.-H. Ma, Y.-H. Wan, Z.-G. Su, Preparation and characterization of uniform-sized chitosan microspheres containing insulin by membrane emulsification and a two-step solidification process, Colloids Surf., B Biointerfaces 50 (2006) 126-135.

[31] J. Wu, W. Wei, L.-Y. Wang, Z.-G. Su, G.-H. Ma, Preparation of uniform-sized pHsensitive quaternized chitosan microsphere by combining membrane emulsification technique and thermal-gelation method, Colloids Surf., B Biointerfaces 63 (2008) 164-175.

[32] G. Vladisavljevic, Influence of process parameters on droplet size distribution in SPG membrane emulsification and stability of prepared emulsion droplets, J. Membr. Sci. 225 (2003) 15-23.

[33] M.T. Stillwell, R.G. Holdich, S.R. Kosvintsev, G. Gasparini, I.W. Cumming Stirred cell membrane emulsification and factors influencing dispersion drop size and uniformity, Ind. Eng. Chem. Res. 46 (2007) 965-972.

[34] M.M. Dragosavac, R.G. Holdich, G.T. Vladisavljević, M.N. Sovilj, Stirred cell membrane emulsification for multiple emulsions containing unrefined pumpkin seed oil with uniform droplet size, J. Membr. Sci. 392-393 (2012) 122-129.

[35] G. Vladisavljevic, H. Schubert, Preparation and analysis of oil-in-water emulsions with a narrow droplet size distribution using Shirasu-porousglass (SPG) membranes, Desalination 144 (2002) 167-172.

[36] M.M. Dragosavac, M.N. Sovilj, S.R. Kosvintsev, R.G. Holdich, G.T. Vladisavljević Controlled production of oil-in-water emulsions containing unrefined pumpkin seed oil using stirred cell membrane emulsification, J. Membr. Sci. 322 (2008) 178-188.

[37] R.G. Holdich, M.M. Dragosavac, G.T. Vladisavljevic, E. Piacentini, Continuous membrane emulsification with pulsed (oscillatory) flow, Ind. Eng. Chem. Res. (2012).

[38] M.M. Dragosavac, G.T. Vladisavljević, R.G. Holdich, M.T. Stillwell, Production of porous silica microparticles by membrane emulsification, Langmuir 28 (2012) 134-143.

[39] C.K.S. Pillai, W. Paul, C.P. Sharma, Chitin and chitosan polymers: chemistry, solubility and fiber formation, Prog. Polym. Sci. 34 (2009) 641-678.

[40] K. Lunkenheimer, K.-D. Wantke, Determination of the surface tension of surfactant solutions applying the method of Lecomte du Noiiy (ring tensiometer), Colloid Polym. Sci. 259 (1981) 354-366.

[41] X. Pan, D. York, J.A. Preece, Z. Zhang, Size and strength distributions of melamine-formaldehyde microcapsules prepared by membrane emulsification, Powder Technol. 227 (2012) 43-50.

[42] B. Thanoo, Controlled release of oral drugs from cross-linked polyvinyl alcohol microspheres, J. Pharm. Pharmacol. 45 (1993) 16-20.

[43] L. Wang, G. Ma, Z. Su, Preparation of uniform sized chitosan microspheres by membrane emulsification technique and application as a carrier of protein drug, J. Control. Release 106 (2005) 62-75.

[44] R. Gillett, K. Gull, Glutaraldehyde - its purity and stability, Histochemie 30 (1972) 162-167.

[45] R. Holdich, Membrane emulsification with oscillating and stationary membranes, Ind. Eng. Chem. Res. 49 (2010) 3810-3817.

[46] V. Schröder, H. Schubert, Production of emulsions using microporous, ceramic membranes, Colloids Surf., A Physicochem. Eng. Asp. 152 (1999) 103-109.

[47] M. Rathbone, J. Hadgraft, M.S. Roberts, Modified-release Drug Delivery Technology, CRC Press, 2002.

[48] A. Imbrogno, M. Dragosavac, E. Piacentini, G.T. Vladisavljević, R.G. Holdich, L Giorno, Polycaprolactone multicore-matrix particle for the simultaneous encapsulation of hydrophilic and hydrophobic compounds produced by membrane emulsification and solvent diffusion processes, Colloids Surf., B Biointerfaces 135 (2015) 116-125.

[49] D.A.R. Paradkar, Biopharmaceutics \& Pharmacokinetics, Nirali Prakashan, 2008.

[50] X. Huang, C.S. Brazel, On the importance and mechanisms of burst release in matrix-controlled drug delivery systems, J. Control. Release 73 (2001) 121136.

[51] G. Feng, Y. Xiong, H. Wang, Y. Yang, Gelation of microemulsions and release behavior of sodium salicylate from gelled microemulsions, Eur. J. Pharm. Biopharm. 71 (2009) 297-302.

[52] S. Puttipipatkhachorn, J. Nunthanid, K. Yamamoto, G. Peck, Drug physical state and drug-polymer interaction on drug release from chitosan matrix films, J. Control. Release. 75 (2001) 143-153. 